\title{
Effects of COVID-19 lockdown on low back pain intensity in chronic low back pain patients: results of the multicenter CONFI-LOMB study
}

\author{
Florian Bailly ${ }^{1}$-Stéphane Genevay ${ }^{2} \cdot$ Violaine Foltz $^{3} \cdot$ Amélie Bohm-Sigrand $^{4} \cdot$ Alain Zagala $^{5} \cdot$ Julien Nizard $^{6}$. \\ Audrey Petit ${ }^{7,8}$
}

Received: 24 June 2021 / Revised: 19 August 2021 / Accepted: 21 September 2021 / Published online: 4 October 2021

(c) The Author(s) 2021

\begin{abstract}
Purpose The COVID-19 pandemic and the extended lockdown are associated with numerous changes in behavior and lifestyles. The objective was to assess the impact of the first lockdown on LBP course among chronic LBP patients.

Methods Descriptive and analytical, cross-sectional, multicenter study, conducted by questionnaire from mid-May to end of June 2020 among patients treated for chronic LBP in 6 French and 1 Swiss center. Collected data concerned changes in LBP intensity during lockdown, lockdown experience, physical activity (PA) practice and sedentary lifestyle prior and during lockdown, recourse to care, consumption of psychoactive substances for LBP, and professional activity and its conditions during lockdown.

Results 360 participants (58.6\% women, $52.1 \pm 13.4$ years) were included of which $65 \%$ were active (63\% keep on working of which $54 \%$ teleworked). LBP got worse in $41.1 \%$, mean VAS went from $49.5 \pm 21.6$ before to $53.5 \pm 22.4$ during lockdown $(p<0.001)$ and needed increase of treatment by $29 \%$ but very few people increased their consumption psychoactive substances for analgesia. Half of participants had well-experienced lockdown. Findings revealed a significant decrease in PA and increase of sedentary during lockdown $(p<0.0001)$. Good experience of lockdown was associated with LBP improvement $(\mathrm{OR}=0.6$ [0.3-0.9]) and decrease of PA with LBP worsening $(\mathrm{OR}=1.9[1.1-3.2])$. Teleworking was also associated with LBP worsening. Gender, age, or BMI did not influence LBP course.

Conclusion These findings indicate that chronic LBP people suffered from increase in self-perceived LBP during lockdown and help to better understand the factors associated with their condition.
\end{abstract}

Keywords COVID-19 $\cdot$ Low back pain $\cdot$ Physical activity $\cdot$ Lockdown experience

\section{Introduction}

The COVID-19, which was declared a global pandemic on 11th March 2020 by the WHO has quickly become a serious challenge, affecting all societies. The context of COVID-19

Audrey Petit

aupetit@chu-angers.fr

1 Pain Unit, Rheumatology Department, Pitié Salpêtrière Hospital, AP-HP, 47-83 boulevard de l'hôpital, 75013 Paris, France

2 Division of Rheumatology, Beau Sejour Hospital, Geneva University Hospitals, 14, CH-1205 Geneva, Switzerland

3 Rheumatology Department, Pitié Salpêtrière Hospital, AP-HP, 47-83 boulevard de l'hôpital, 75013 Paris, France

4 Rheumatology Department, Dijon University Hospital, 14 rue Gaffarel, 21000 Dijon, France pandemic generates health concerns but is also associated with numerous changes in behavior and lifestyles, in particular, due to the extended lockdown [1-5]. Although social lockdown remains the best non-pharmacological solution to decelerate the fast transmission of the virus, it is likely

5 Rheumatology Practice, 17 Boulevard Agutte Sembat, 38000 Grenoble, France

6 Pain, Palliative and Supportive Care Department, University Hospital of Nantes, 1 Place Alexis-Ricordeau, 44093 Nantes, France

7 University of Angers, Inserm, EHESP, Irset, UMR-S 1085, Angers, France

8 Department of Occupational Medecine, University Hospital of Angers, 4 rue Larrey, 49933 Angers cedex 9, France 
generating negative consequences on mental health and lifestyle behaviors. Thus, recent studies demonstrated that lockdown could dramatically impact lifestyle activities globally, including participation in sports and physical activity (PA) practice $[1,6-8]$.

Numerous studies have shown that the onset of low back pain (LBP), its recurrence, and, even more, its evolution towards chronicity, are the consequences of a complex interrelation between physical, psychological, social, and professional factors, known as "bio-psycho-social model" [9]. If the prevention of LBP and chronic LBP, as well as their management, is based primarily on the practice of regular sports and PA, other psychological (stress, anxiety, depression, catastrophizing), socioeconomic factors (low level of education or resources), professional (ergonomic factors, job dissatisfaction), etc. also have a major role in the LBP course $[10,11]$. Though not identical conditions or contexts, we can cautiously suppose that COVID-19 pandemic, and more particularly the lockdown that we underwent in spring 2020, had and will have significant consequences for people with chronic LBP as that have been suggested in previous studies on chronic pain patients $[8,12]$. However, the interference of the different factors related to lockdown had potentially different consequences at the individual level. It seemed therefore difficult to predict what would be the evolution of lumbar symptoms in this population. Indeed, if we can speculate consider that the decrease in PA practice and a bad lockdown experience in this context of insecurity could lead to a pain increase, we could just as well speculate consider that the decrease in stress at work, heavy physical work, or even commuting times, on the contrary, could have a positive effect.

The main objective of this study was to assess the impact of the spring 2020 lockdown on LBP intensity course in chronic LBP patients. The secondary goal was to study the impact on LBP course of the pandemic experience, behavior and lifestyles, and occupational conditions during lockdown.

\section{Methods}

\section{Study design and setting}

We report findings on a descriptive and analytical, crosssectional, multicenter study on the impact of lockdown on the LBP intensity in chronic LBP patients (CONFI-LOMB study). CONFI-LOMB was conducted by questionnaire, from May 12 to June 30, 2020. The project's steering group was composed of seven French and Swiss rheumatologists, all members of the French Rheumatology Society. Seven centers were involved in the study: University Hospital of Angers, Dijon, Genève, Nantes, two of Paris as well as private rheumatology consulting practice in Grenoble.
Lockdown time and the limitation were similar in both countries.

\section{Participants screening and inclusion}

Inclusion criteria were: (1) to be an adult (men or women), (2) to have undergone a consultation for a common chronic LBP between January 1, 2020, and March 17, 2020 (start of the French lockdown) included. Common chronic LBP was defined as non-specific LBP (i.e. LBP for which the specialist has ruled out malignant, traumatic, infectious, or inflammatory origin thanks to clinical, biological, and/or imaging explorations) lasting for at least 3 months without improvement, (3) consent to participate in this research.

Exclusion criteria were: to suffer from another chronic pain syndrome interfering with daily life activities (fibromyalgia, etc.), to have comorbidities limiting the practice of sports and PA (severe heart or respiratory diseases, claudication due to lower limbs arteriopathy, etc.), poor understanding of the French language and inability to answer a questionnaire (illiteracy, no internet or phone access, etc.).

The physicians contacted eligible patients by phone or sent them a form or an electronic version of the questionnaire after sending an information letter. When done by phone, the physicians provided oral information on the study and answered questions. The first part of the questionnaire underlines the goal of the study and the contact details of the person to contact in case of questions.

\section{Ethical aspects}

During the informed consent process, survey participants were assured all data would be used only for research purposes. Participants' answers were anonymous and confidential. Additionally, participants were able to stop study participation at any stage of the questionnaire. If doing so, their responses would not be registered. Participants were requested to be honest in their responses.

This research involving the human being was qualified as non-interventional research because it was solely based on the completion of a questionnaire. The study file was submitted to the Ile-de France X Committee for the Protection of Persons who issued a favorable opinion to implement this research on May 11, 2020 (identification $\mathrm{N}^{\circ} 2020$-AO141732). ClinicalTrials.gov identifier: NCT04406363.

\section{Outcomes and risk factors measurement}

An ad hoc questionnaire was prepared in accordance with the available literature and the feedback from patients collected by the members of the study's steering group during lockdown. The questionnaire was composed of 32 questions divided into seven parts: (1) sociodemographic 
data, (2) condition and experience of lockdown, (3) medical status vis-à-vis of the coronavirus, (4) anthropometric and LBP pain data, (5) consumption of care and psychoactive substances, (6) time spend for PA and sedentary activities, in accordance with usual measurement scales, (8) occupational condition and consequences felt on LBP. The questionnaire was completed in French from May 12 to June 30, 2020.

The primary outcome was a change in LBP intensity prior to the lockdown and during it assessed by a 7-point Likert scale (from much improved to much worsened). A clear definition and a model of response were done to help the subjects answer this question. The second outcomes were: LBP intensity before and during lockdown (Visual Analog Scale (VAS)), the experience of lockdown, the PA practice (sports and leisure) before and during lockdown (less than $2 \mathrm{~h}$ a week, from 2 to $4 \mathrm{~h}$ a week, more than $4 \mathrm{~h}$ a week), time spent in sedentary activities (less than $3 \mathrm{~h}$ a day, from 3 to $7 \mathrm{~h}$ a day, more than $7 \mathrm{~h}$ a day), occurrence of a SARSCoV-2 infection and its level of severity, recourse to care, consumption of medication and psychoactive substances intended for LBP analgesia, continuation of occupation and its conditions (at the workplace, teleworking).

\section{Analyses}

Given the exploratory nature of this study, and due to the lack of data at the time of the study setting, the number of subjects required to ensure representativeness was estimated, empirically with regard to the active lines of the participating centers, at 50 patients per physician ( 350 subjects in total).

Results were expressed as mean \pm standard deviation for continuous data or as count and percentage for categorical data. A paired t-test was employed to compare VAS of patients before and during lockdown. Wald Chi-square tests were used for comparing categorical variables. Due to the low number of people within some categories of evolution of LBP, the modalities "much improved", "moderately improved", "slightly improved", and "stable" were combined within the same "stable or improved pain" modality, and the modalities "slightly worsened", "moderately worsened" and "much worsened" were combined within a second "worsened" modality. The association between risk factors and LBP course (worsening versus unchanged or improvement) was estimated using logistic regression. Significant variables with a $p$-value under 0.20 in univariate analysis were included in the multivariate logistic regression model. Age, sex, and body mass index (BMI) were forced in the final model. The significant level $(p)$ in the final model has been defined as 0.05 . Data analyses were performed with version 3.6.1 of the $\mathrm{R}$ software.

\section{Results}

\section{Sample description}

Among patients who met the inclusion criteria, a total of 360 were offered the opportunity and accepted to participate in this study. The lockdown duration was the same for every participant. The sample consisted of 149 men and 211 women, from rural and urban areas of the concerned regions, with a mean age of $52.1 \pm 13.4$ years (from 19 to 91 years). BMI was comprised between 14.7 and $44.4 \mathrm{~kg} / \mathrm{m}^{2}$ with a mean of $26.1 \pm 4.9 \mathrm{~kg} / \mathrm{m}^{2}$ and remained stable during lockdown. The large majority of the participants had suffered from LBP for more than two years. Most participants lived in couple $(71.8 \%)$ and had an occupation $(65.0 \%)$. Among the 230 workers, $63 \%$ keep on working of which $54 \%$ teleworked during lockdown. Near $58 \%$ of teleworkers declared to have a dedicated homework station and $47 \%$ to have suitable equipment for teleworking. Half of the participants $(51.7 \%)$ declared having well-experienced lockdown. Finally, 6.4\% of people were infected by the SARS-CoV-2 with a low rate of severe symptoms (Table 1).

\section{LBP, recourse to care and treatment, and physical activity during lockdown}

LBP was unchanged or improved in almost 59\% while more than $41 \%$ of them got worse. The mean pain VAS course went from $49.5 \pm 21.6$ before lockdown to $53.5 \pm 22.4$ during lockdown $(\mathrm{p}<0.001)$. Near $30 \%$ of participants visited a doctor or increased their treatment for LBP while $12.1 \%$ decreased it during lockdown. Very few patients increased their consumption of alcohol, tobacco, cannabis, or anxiolytics to decrease pain (Table 2). Lockdown significantly impacted participation in PA practice which globally decreased during lockdown $(p<0.0001)$. Overall, $30 \%$ of patients decreased their practice of PA while less than $14 \%$ increased it. In parallel, sedentary lifestyle significantly increased during lockdown $(p<0.0001)$ with a proportion of people spending more than $7 \mathrm{~h}$ a day in sedentary activities going from 19 to $32 \%$ (Table 3 ).

\section{Factors associated with LBP course}

Univariate analyses show that LBP increased significantly more often in case of bad experience of lockdown, decrease or low practice of PA, and teleworking during lockdown $(p<0.20)$. On the other hand, LBP course was not influenced by sedentary lifestyle or SARS-COV-2 infection (Table 4).

Multivariate analyses highlight that good experience of lockdown $\left(\mathrm{OR}=0.6 \mathrm{CI}_{95 \%}[0.3-0.9]\right)$ was a protective factor 
Table 1 Patients characteristics

\begin{tabular}{|c|c|c|}
\hline & $N$ & $\% *$ \\
\hline \multicolumn{3}{|l|}{ Gender } \\
\hline Male & 149 & 41.4 \\
\hline Female & 211 & 58.6 \\
\hline \multicolumn{3}{|l|}{ Age } \\
\hline $18-34$ years & 33 & 9.2 \\
\hline $35-49$ years & 134 & 37.2 \\
\hline $50-64$ years & 125 & 34.7 \\
\hline$\geq 65$ years & 68 & 18.9 \\
\hline \multicolumn{3}{|l|}{ BMI before lockdown } \\
\hline$<25 \mathrm{~kg} / \mathrm{m}^{2}$ & 156 & 43.6 \\
\hline$\geq 25 \mathrm{~kg} / \mathrm{m}^{2}$ & 202 & 56.4 \\
\hline \multicolumn{3}{|l|}{ LBP duration } \\
\hline $3-6$ months & 7 & 2.0 \\
\hline $6-24$ months & 50 & 14.1 \\
\hline$>24$ months & 297 & 83.9 \\
\hline \multicolumn{3}{|l|}{ Marital status } \\
\hline Couple & 255 & 71.8 \\
\hline Single & 100 & 28.2 \\
\hline \multicolumn{3}{|l|}{ Occupational status } \\
\hline Active & 230 & 65.0 \\
\hline Non-active & 124 & 35.0 \\
\hline \multicolumn{3}{|c|}{ Keep on working during lockdown } \\
\hline Yes & 129 & 63.2 \\
\hline No & 75 & 36.8 \\
\hline \multicolumn{3}{|l|}{ Telework } \\
\hline Yes & 67 & 54.0 \\
\hline No & 57 & 46.0 \\
\hline \multicolumn{3}{|c|}{ Workstation dedicated for telework } \\
\hline Yes & 39 & 58.2 \\
\hline No & 28 & 41.8 \\
\hline \multicolumn{3}{|c|}{ Equipment adapted to telework } \\
\hline Yes & 28 & 46.7 \\
\hline No & 32 & 53.3 \\
\hline \multicolumn{3}{|l|}{ Lockdown experience } \\
\hline Good & 184 & 51.7 \\
\hline Neither good or bad & 104 & 29.2 \\
\hline $\mathrm{Bad}$ & 68 & 19.1 \\
\hline \multicolumn{3}{|l|}{ SARS-COV-2 infection } \\
\hline Yes & 23 & 6.4 \\
\hline No & 335 & 93.6 \\
\hline \multicolumn{3}{|c|}{ Severity of SARS-COV-2 infection } \\
\hline Few or no symptoms & 11 & 47.8 \\
\hline Discomfort in ADL & 7 & 30.4 \\
\hline Hospitalization & 1 & 4.3 \\
\hline Intensive care & 0 & 0 \\
\hline
\end{tabular}

$A D L$ Activities of daily living; $B M I$ Body mass index; $L B P$ Low back pain

*Percentages without missing data
Table 2 LBP and repercussions during lockdown

\begin{tabular}{|c|c|c|}
\hline & $N$ & $\%$ \\
\hline \multicolumn{3}{|l|}{ Course of LBP } \\
\hline Much improved & 11 & 3.1 \\
\hline Moderately improved & 22 & 6.1 \\
\hline Slightly improved & 18 & 5.0 \\
\hline Stable & 161 & 44.7 \\
\hline Slightly worsened & 65 & 18.1 \\
\hline Moderately worsened & 50 & 13.9 \\
\hline Much worsened & 33 & 9.2 \\
\hline \multicolumn{3}{|l|}{$\operatorname{VAS}(/ 100)$} \\
\hline Before lockdown (mean \pm sd) & $49.6 \pm 21.5$ & $<0.001^{\mathrm{a}}$ \\
\hline During lockdown $($ mean $\pm \mathrm{sd})$ & $53.5 \pm 22.4$ & \\
\hline \multicolumn{3}{|c|}{ Increase of treatment /consultation for LBP } \\
\hline Yes & 103 & 29.0 \\
\hline No & 252 & 71.0 \\
\hline \multicolumn{3}{|l|}{ Decrease of treatment for LBP } \\
\hline Yes & 41 & 12.1 \\
\hline No & 297 & 87.9 \\
\hline \multicolumn{3}{|l|}{ Increase of Tabaco for LBP } \\
\hline Yes & 24 & 7.2 \\
\hline No & 311 & 92.8 \\
\hline \multicolumn{3}{|l|}{ Increase of alcohol for LBP } \\
\hline Yes & 18 & 5.4 \\
\hline No & 316 & 94.6 \\
\hline \multicolumn{3}{|l|}{ Increase of cannabis for LBP } \\
\hline Yes & 2 & 0.6 \\
\hline No & 328 & 99.4 \\
\hline \multicolumn{3}{|l|}{ Increase of anxiolytics for LBP } \\
\hline Yes & 52 & 15.1 \\
\hline No & 292 & 84.9 \\
\hline
\end{tabular}

LBP Low back pain; VAS Visual Analog Scale

${ }^{\text {a}}$ Paired $t$-test

Table 3 Physical activity and sedentary lifestyle

\begin{tabular}{|c|c|c|c|c|c|}
\hline & \multicolumn{2}{|c|}{ Before lockdown } & \multicolumn{2}{|c|}{ During lockdown } & \multirow[t]{2}{*}{$P$ value $^{\mathrm{a}}$} \\
\hline & $\mathrm{N}$ & $\%$ & $\mathrm{~N}$ & $\%$ & \\
\hline \multicolumn{6}{|c|}{ Physical activity } \\
\hline$<2$ h/week & 121 & 34.4 & 170 & 49.0 & $<0.0001$ \\
\hline $2-4 \mathrm{~h} /$ week & 118 & 33.5 & 84 & 24.2 & \\
\hline$>4 \mathrm{~h} /$ week & 113 & 32.1 & 93 & 26.8 & \\
\hline \multicolumn{6}{|c|}{ Sedentary lifestyle } \\
\hline$<3$ h/day & 167 & 47.9 & 84 & 27.7 & $<0.0001$ \\
\hline 3-7 h/day & 116 & 33.2 & 123 & 40.6 & \\
\hline$>7$ h/day & 66 & 18.9 & 96 & 31.7 & \\
\hline
\end{tabular}

${ }^{\text {a }}$ Pearson chi-square tests 
Table 4 Related factors with LBP course

\begin{tabular}{llll}
\hline & $\begin{array}{l}\text { Decrease or } \\
\text { unchanged of } \\
\text { LBP }\end{array}$ & $\begin{array}{l}\text { Increase of } \\
\text { LBP }\end{array}$ & \\
\cline { 1 - 2 }$\quad \%$ & & \\
\hline
\end{tabular}

\section{Lockdown experience}

$\begin{array}{llllll}\text { Good } & 124 & 59.3 & 60 & 40.8 & 0.0009\end{array}$

$\begin{array}{lllll}\text { Neither good or bad } \quad 56 & 26.8 \quad 48 & 32.7\end{array}$

$\begin{array}{lllll}\mathrm{Bad} & 29 & 13.9 & 39 & 26.5\end{array}$

Physical activity during lockdown

$\begin{array}{lllll}<2 \mathrm{~h} / \text { week } & 87 & 42.4 & 83 & 58.5 \\ 2-4 \mathrm{~h} / \text { week } & 54 & 26.3 & 30 & 21.1 \\ >4 \mathrm{~h} / \text { week } & 64 & 31.2 & 29 & 20.4\end{array}$

Evolution of physical activity before/during lockdown

$\begin{array}{lllll}\text { Increase } & 33 & 16.4 & 14 & 9.9\end{array}$

$\begin{array}{lllll}\text { No change } & 122 & 60.7 & 70 & 49.3\end{array}$

$\begin{array}{lllll}\text { Decrease } & 46 & 22.9 & 58 & 40.8\end{array}$

Sedentary lifestyle during lockdown

$\begin{array}{llllll}<3 \text { h/day } & 55 & 29.9 & 29 & 24.4 & 0.529 \\ 3-7 \text { h/day } & 71 & 38.6 & 52 & 43.7 & \\ >7 \text { h/day } & 58 & 31.5 & 38 & 31.9 & \\ \text { SARS-COV-2 infection } & & & & & \\ \quad \text { Yes } & 12 & 5.7 & 11 & 7.5 & 0.498 \\ \text { No } & 199 & 94.3 & 136 & 92.5 & \end{array}$

Keep on working during lockdown

\begin{tabular}{|c|c|c|c|c|c|}
\hline Yes & 84 & 65.6 & 45 & 59.2 & 0.359 \\
\hline No & 44 & 34.4 & 31 & 40.8 & \\
\hline \multicolumn{6}{|c|}{ Telework } \\
\hline Yes & 39 & 48.1 & 28 & 65.1 & \multirow[t]{2}{*}{0.069} \\
\hline No & 42 & 51.9 & 15 & 34.9 & \\
\hline \multicolumn{6}{|c|}{ Workstation dedicated to telework } \\
\hline Yes & 25 & 64.1 & 14 & 50.0 & \multirow[t]{2}{*}{0.249} \\
\hline No & 14 & 35.9 & 14 & 50.0 & \\
\hline \multicolumn{6}{|c|}{ Equipment adapted to telework } \\
\hline Yes & 19 & 51.4 & 9 & 39.1 & \multirow[t]{2}{*}{0.355} \\
\hline No & 18 & 48.6 & 14 & 60.9 & \\
\hline
\end{tabular}

${ }^{\mathrm{a}}$ Wald Chi-square test

of LBP worsening and decrease of PA practice during lockdown $\left(\mathrm{OR}=1.9 \mathrm{CI}_{95 \%}[1.1-3.2]\right)$ was significantly associated with LBP worsening. On the other hand, gender, age, BMI did not influenced LBP course during lockdown (Table 5).

\section{Discussion}

We set out to understand how the COVID-19 pandemic and associated lockdown restrictions, impacted individuals with chronic LBP in terms of their pain experience. The findings reveal that LBP has remained unchanged or has worsened for the majority of patients during lockdown. Bad experience of
Table 5 Multivariate analysis of low back pain course (worsening versus unchanged or improvement) according to patients characteristics and life conditions during lockdown

\begin{tabular}{|c|c|c|c|}
\hline & Adjusted OR & IC95\% & $p$-value ${ }^{\mathrm{a}}$ \\
\hline \multicolumn{4}{|l|}{ Gender } \\
\hline Male & 1 & - & 0.255 \\
\hline Female & 1.33 & $0.82-2.16$ & \\
\hline \multicolumn{4}{|l|}{ Age } \\
\hline $18-34$ years & 1 & - & 0.894 \\
\hline $35-49$ years & 1.20 & $0.53-2.78$ & \\
\hline $50-64$ years & 0.98 & $0.43-2.29$ & \\
\hline$\geq 65$ years & 1.17 & $0.43-3.25$ & \\
\hline \multicolumn{4}{|l|}{ BMI before lockdown } \\
\hline$<25 \mathrm{~kg} / \mathrm{m}^{2}$ & 1 & - & 0.515 \\
\hline$\geq 25 \mathrm{~kg} / \mathrm{m}^{2}$ & 1.17 & $0.73-1.89$ & \\
\hline \multicolumn{4}{|c|}{ Course of physical activity practice during versus before lockdown } \\
\hline Increase & 0.78 & $0.37-1.58$ & 0.024 \\
\hline Constant & 1 & - & \\
\hline Decrease & 1.88 & $1.12-3.17$ & \\
\hline \multicolumn{4}{|l|}{ Lockdown experience } \\
\hline Good & 0.55 & $0.32-0.93$ & 0.004 \\
\hline Neither good or bad & 1 & - & \\
\hline $\mathrm{Bad}$ & 1.45 & $0.74-2.84$ & \\
\hline
\end{tabular}

$B M I$ Body mass index

${ }^{\mathrm{a}}$ Wald Chi-square test

lockdown, low or decrease in levels of PA appeared the main associated factors for LBP worsening. Teleworking was also associated with LBP worsening. However, very few people increase their consumption of tobacco or psychoactive substances.

Concerning LBP course, our sample of chronic LBP patients was more adversely affect by lockdown than the general population among which the majority stated that their lower back problems were unchanged (62.6\%), a quarter felt better, while $11.9 \%$ felt worse in a French Public Health Institute survey $(n=1,111)$ [13]. An Italian national study reported that almost one in two Italians declared having suffered from back pain more often during lockdown [14]. Our findings are also in accordance with those of Fallon et al. who observed that people with chronic pain reported self-perceived increases in levels of pain severity during lockdown in the UK [8]. Regarding mean VAS evolution during lockdown, we assumed that even statistically significant, the course from $49.5 \pm 21.6$ before, to $53.4 \pm 22.4$ during lockdown could be interpreted as at the limit of clinical significance and below the minimal clinically important changes in chronic pain intensity measured on a numerical rating scale [15]. Even if VAS is describe as the most sensitive method for measuring pain and can be also used reliably in chronic clinical pain, it should be taken into account 
that non-specific chronic LBP is especially characterized by undulant course of pain intensity [16]. Our findings could therefore only be related to the usual course of VAS in chronic LBP patients.

Previous studies have found a significant effect of the COVID-19 pandemic on social participation and life satisfaction scores [1-5] and the decrease in individual wellbeing has already been observed during similar pandemic crises (2002-2004 SARS outbreak) [17, 18]. Our findings highlight a bad or neither good nor bad lockdown experience in almost half of patients. These findings confirm that social distancing during lockdown was associated with less satisfied persons $[1,5,19]$. Patients with chronic pain are more likely to suffer from self-isolating and it can be assumed a mediating role on perceived changes in pain during lockdown and its experience [8]. Moreover, amplification of bodily sensations' perception or change as symptoms of being ill which impacts on chronic pain experience was recently shown to be exacerbated by the current pandemic, particularly in vulnerable populations $[8,20]$. Finally, bad experience is usually associated with changes in health behavior, in particular tobacco consumption and alcohol misuse [4, 21]. However, we did not observe a clear increase in psychoactive substances consumptions intended to reduce pain in our sample.

COVID-19 lockdown has caused significant changes in individuals' lifestyle and has been likely to decrease the number of times per week devoted to participating PA and to increase the time spent sitting. This negative effect seems to affect a large proportion of people around the world and all PA intensity levels (vigorous, moderate, walking, and overall), and an increase from 16 to $40 \%$ of people spending more than $8 \mathrm{~h}$ a day in sedentary activities could even be observed $[4,6]$. The reported overall decline in PA is likely a consequence of social distancing, travel restrictions, closure of usual exercise venues, etc. Moreover, recent study reported a lower LBP prevalence among individuals who regularly practiced $\mathrm{PA}$ and the negative effect of prolonged sitting on LBP intensity [22-24]. The results of our study concurred with these findings. Indeed, perceived decrease in levels of PA seems to be independently related to perceptions of increased pain and physical inactivity promotes physical deconditioning which exacerbates LBP during activity $[8,25]$. Previous studies have also highlighted the importance of catastrophizing in chronic pain population during response to high-stress situations [26, 27]. In chronic LBP patients, catastrophizing contributes to hypervigilance and fear related to pain and results in avoidance of daily activities and decrease levels of PA [28] but we, unfortunately, did not measure this parameter.

For most employees, teleworking which has been implemented by many companies during lockdown has been the first experience. Although teleworking allows reducing commuting time, and better control overtime schedule, it has the disadvantages of monitoring performance, communication problems, no clear separation between home and work tasks, and unsuitability with all works [29]. Moreover, the home environment is likely to be faulty in many aspects. In particular, the absence of ergonomic office facilities at home may impede the adoption of a healthy posture and may promote the onset of musculoskeletal disorders [25, 30, 31]. Homeworking may cause also stress, and isolation, which influences job effectiveness, well-being, and work-life balance [30]. Our results showed that teleworking seemed to affect LBP significantly. Firstly, effect of teleworking on LBP could have been underestimated in our study because subjects were practicing this job type for a too-brief period to produce the adverse effects [31]. Secondly, the multifactorial nature of LBP, and in particular, psychosocial factors (stress, job satisfaction, isolation, etc.) could have played a role in LBP course and that could be the reason why teleworking did not appear as a separate associated risk in our multivariate analysis. Finally, the French Public Health Institute found that the incidence of LBP was about 2.5 times higher among workers who had been newly placed on telework during lockdown and that among workers with pre-existing LBP, those who had continued telework, as usual, had more luck to see their LBP evolve favorably, but our study did not allow us to examine these two types of situations [32].

\section{Strengths and limitations}

The strength of this study is that the data were collected very quickly after the first COVID-19 lockdown using a fully anonymous questionnaire. The multicenter design of the study allowed the inter-regional variability of the lockdown conditions to be taken into account. Regarding the methodological issues, possible limitations could be related to (1) the cross-sectional design assessing "before" lockdown data retrospectively, (2) the self-administered and anonymous computerized questionnaire which prevented us from establishing an accurate flowchart of respondents. However, given that the lockdown was a sudden measure, we were obviously not able to develop and spread the survey "before" lockdown to have an ideal control condition, and (3) the study was carried out among patients from tertiary centers of chronic LBP management. To our knowledge, no study has specifically looked at the consequences of confinement in chronic LBP patients specifically. Our results highlight the deleterious impact of confinement on LBP and improve our understanding of the involved factors. 


\section{Conclusion}

The lockdown due to the COVID-19 pandemic led to a tendency for stable to worsening LBP intensity among chronic LBP patients. Our results reveal psycho-social pressure during lockdown. Moreover, chronic LBP patients are already at an increased risk of being hypoactive which was aggraded by lockdown. Given the established benefits of PA on LBP, additional strategies to promote PA are needed. Lockdown encouraged greater use of Information and Communications Technology (ICT). Therefore, future PA and/or psychological support interventions to foster a more active and healthy lockdown lifestyle during pandemic could be based on ICT solutions. Finally, teleworking exposes particularly workers to ergonomic risk factors likely to increase LBP intensity. Particular intention should be paid to the workplace comfort at home.

Supplementary Information The online version contains supplementary material available at https://doi.org/10.1007/s00586-021-07007-8.

Acknowledgments Authors would like to thank Anne-Lise Rolland, Julie Bodin, and Lou Roquelaure for their considerable help with the database management and the statistical analysis. We thank Charlotte Regnault-Leuger, Antoine Thoron, Christine Fayolle, and Maëva Benjamen who greatly helped to the questionnaire diffusion. We are also grateful to all participants who accepted to participate in the CONFILOMB study.

Author contributions All authors contributed to the study's conception and design. Data collection was performed by all the authors in their own center. Analyses were performed by Audrey Petit and Florian Bally. The first draft of the manuscript was written by Audrey Petit and all authors commented on previous versions of the manuscript. All authors read and approved the final manuscript.

Funding No funds, grants, or other support were received.

\section{Declarations}

Conflict of interest Authors declare they have no conflict of interest, no financial interests to disclose.

Open Access This article is licensed under a Creative Commons Attribution 4.0 International License, which permits use, sharing, adaptation, distribution and reproduction in any medium or format, as long as you give appropriate credit to the original author(s) and the source, provide a link to the Creative Commons licence, and indicate if changes were made. The images or other third party material in this article are included in the article's Creative Commons licence, unless indicated otherwise in a credit line to the material. If material is not included in the article's Creative Commons licence and your intended use is not permitted by statutory regulation or exceeds the permitted use, you will need to obtain permission directly from the copyright holder. To view a copy of this licence, visit http://creativecommons.org/licenses/by/4.0/.

\section{References}

1. Ammar A, Chtourou H, Boukhris O, Trabelsi K, Masmoudi L, Brach $\mathrm{M}$ et al (2020) COVID-19 home confinement negatively impacts social participation and life satisfaction: a worldwide multicenter study. Int J Environ Res Public Health 17(17):6237

2. Lima CKT, Carvalho PMM, Lima IAAS, Nunes JVAO, Saraiva JS, de Souza RI, da Silva CGL, Neto MLR (2020) The emotional impact of Coronavirus 2019-nCoV (new Coronavirus disease). Psychiatry Res 287:112915

3. Qiu J, Shen B, Zhao M, Wang Z, Xie B, Xu Y (2020) A nationwide survey of psychological distress among Chinese people in the COVID-19 epidemic: implications and policy recommendations. Gen Psychiatr 33(2):e100213

4. Stanton R, To Q, Khalesi S, Williams S, Alley S, Thwaite T et al (2020) Depression, anxiety and stress during COVID-19: associations with changes in physical activity, sleep, tobacco and alcohol use in australian adults. Int J Environ Res Public Health 17(11):4065

5. Zhang SX, Wang Y, Rauch A, Wei F (2020) Unprecedented disruption of lives and work: health, distress and life satisfaction of working adults in China one month into the COVID-19 outbreak. Psychiatry Res 288:112958

6. Ammar A, Brach M, Trabelsi K, Chtourou H, Boukhris O, Masmoudi L et al (2020) A effects of COVID-19 home confinement on eating behaviour and physical activity: results of the ECLBCOVID19 international online survey. Nutrients 12(6):1583

7. Hossain MM, Sultana A, Purohit N (2020) Mental health outcomes of quarantine and isolation for infection prevention: a systematic umbrella review of the global evidence. Epidemiol Health 42:e2020038

8. Fallon N, Brown C, Twiddy H, Bria E, Frank B, Nurmikko T, Stancak A (2020) Adverse effects of COVID-19-related lockdown on pain, physical activity and psychological well-being in people with chronic pain. Br J Pain. https://doi.org/10.1177/2049463720 973703

9. Waddell G (1987) A new clinical model for the treatment of lowback pain. Spine 12:632-644

10. Loisel P, Abenhaim L, Durand P, Esdaile JM, Suissa S, Gosselin L, Simard R, Turcotte J, Lemaire J (1997) A populationbased, randomized clinical trial on back pain management. Spine 22(24):2911-2918

11. Nguyen C, Poiraudeau S, Revel M, Papelard A (2009) Chronic low back pain: risk factors for chronicity. Rev Rhum 76:537-542

12. Endstrasser F, Braito M, Linser M, Spicher A, Wagner M, Brunner A (2020) The negative impact of the COVID-19 lockdown on pain and physical function in patients with end-stage hip or knee osteoarthritis. Knee Surg Sports Traumatol Arthrosc 28(8):2435-2443

13. Chazelle É, Chan-Chee C, Fouquet N (2020) Low back pain rate and evolution in different work situations during covid-19 epidemic lockdown from 17 march to 10 may 2020, in metropolitan France [In French]. Bulletin épidémiologique hebdomadaire $26: 512-21$

14. Mal di Quarantena: Il mal di Schiena è Stato il Disturbo più Diffuso Durante il Lockdown, ne ha Sofferto 1 Italiano su 2 Federchimica Assosalute-Associazione Nazionale Farmaci di Automedicazione. [In Italian] Available online: https://www.feder chimica.it/webmagazine/dettaglio-news/2020/05/29/mal-di-schie na-assosalute. Accessed 23 June 2021.

15. Salaffi F, Stancati A, Silvestri CA, Ciapetti A, Grassi W (2004) Minimal clinically important changes in chronic musculoskeletal pain intensity measured on a numerical rating scale. Eur J Pain $8(4): 283-291$ 
16. Ogon M, Krismer M, Söllner W, Kantner-Rumplmair W, Lampe A (1996) Chronic low back pain measurement with visual analogue scales in different settings. Pain 64(3):425-428

17. Hawryluck L, Gold WL, Robinson S, Pogorski S, Galea S, Styra R (2004) SARS control and psychological effects of quarantine, Toronto. Canada Emerg Infect Dis 10(7):1206-1212

18. Reynolds DL, Garay JR, Deamond SL, Moran MK, Gold W, Styra R (2008) Understanding, compliance and psychological impact of the SARS quarantine experience. Epidemiol Infect 136(7):997-1007

19. Pancani L, Marinucci M, Aureli N, Riva P (2020) Forced social isolation and mental health: A study on 1006 Italians under COVID-19 quarantine. https://doi.org/10.31234/osf.io/uacfj

20. Asmundson GJG, Taylor S (2020) How health anxiety influences responses to viral outbreaks like COVID-19: what all decisionmakers, health authorities, and health care professionals need to know. J Anxiety Disord 71:102211

21. Stubbs B, Vancampfort D, Firth J, Solmi M, Siddiqi N, Smith L, Carvalho AF, Koyanagi A (2018) Association between depression and smoking: a global perspective from 48 low- and middleincome countries. J Psychiatr Res 103:142-149

22. Šagát P, Bartík P, Prieto González P, Tohănean DI, Knjaz D (2020) Impact of COVID-19 quarantine on low back pain intensity, prevalence, and associated risk factors among adult citizens residing in Riyadh (Saudi Arabia): a cross-sectional study. Int J Environ Res Public Health 17(19):7302

23. Alzahrani H, Mackey M, Stamatakis E, Zadro JR, Shirley D (2019) The association between physical activity and low back pain: a systematic review and meta-analysis of observational studies. Sci Rep 9(1):8244

24. Taulaniemi A, Kankaanpää M, Tokola K, Parkkari J, Suni JH (2019) Neuromuscular exercise reduces low back pain intensity and improves physical functioning in nursing duties among female healthcare workers; secondary analysis of a randomised controlled trial. BMC Musculoskelet Disord 20(1):328

25. Mayer TG, Smith SS, Keeley J, Mooney V (1985) Quantification of lumbar function. Part 2: sagittal plane trunk strength in chronic low-back pain patients. Spine 10(8):765-72
26. Sturgeon JA, Zautra AJ, Arewasikporn A (2014) A multilevel structural equation modeling analysis of vulnerabilities and resilience resources influencing affective adaptation to chronic pain. Pain 155(2):292-298

27. Noyman-Veksler G, Shalev H, Brill S, Rudich Z, Shahar G (2018) Chronic pain under missile attacks: role of pain catastrophizing, media, and stress-related exposure. Psychol Trauma 10(4):463-469

28. Vlaeyen JWS, Linton SJ (2000) Fear-avoidance and its consequences in chronic musculoskeletal pain: a state of the art. Pain 85(3):317-332

29. The Balance Careers. The pros and cons of a flexible work schedule. Available online: https://www.thebalancecareers.com/advan tages-and-disadvantages-of-flexible-work-schedules-1917964. (Accessed 23 June 2021).

30. Grant CA, Wallace LM, Spurgeon PC (2013) An exploration of the psychological factors affecting remote e-worker's job effectiveness, well-being and work-life balance. Empl Relat 35:527-546

31. Moretti A, Menna F, Aulicino M, Paoletta M, Liguori S, Iolascon G (2020) Characterization of home working population during COVID-19 emergency: a cross-sectional analysis. Int J Environ Res Public Health 17(17):6284

32. Lambert A, Cayouette-Remblière J, Guéraut É, Le Roux G, Bonvalet C, Girard V, Langlois L (2020) Work and its facilities: what the covid-19 pandemic has changed for the French [In French]. Popul Soc 579(7):1-4

Publisher's Note Springer Nature remains neutral with regard to jurisdictional claims in published maps and institutional affiliations. 